\title{
Consumption of ultra-processed foods and likely impact on human health. Evidence from Canada
}

\author{
Jean-Claude Moubarac ${ }^{1,2, *}$, Ana Paula Bortoletto Martins ${ }^{1}$, Rafael Moreira Claro ${ }^{1}$, \\ Renata Bertazzi Levy ${ }^{1,3}$, Geoffrey Cannon ${ }^{4}$ and Carlos Augusto Monteiro ${ }^{1,5}$ \\ 'Núcleo de Pesquisas Epidemiológicas em Nutricão e Saúde, Universidade de São Paulo, Av. Dr Arnaldo 715, \\ 01246-904 São Paulo, SP, Brasil: ²Département de Nutrition, Université de Montréal, Montréal, Canada: \\ ${ }^{3}$ Departamento de Medicina Preventiva, Faculdade de Medicina, Universidade de São Paulo, São Paulo, Brasil: \\ ${ }^{4}$ World Public Health Nutrition Association, Rio de Janeiro, Brazil: ${ }^{5}$ Departamento de Nutricão, Faculdade de \\ Saúde de Pública, Universidade de São Paulo, São Paulo, Brasil
}

Submitted 19 March 2012: Final revision received 18 September 2012: Accepted 19 September 2012: First published online 21 November 2012

\begin{abstract}
Objective: To investigate consumption of ultra-processed products in Canada and to assess their association with dietary quality.

Design: Application of a classification of foodstuffs based on the nature, extent and purpose of food processing to data from a national household food budget survey. Foods are classified as unprocessed/minimally processed foods (Group 1), processed culinary ingredients (Group 2) or ultra-processed products (Group 3).

Setting: All provinces and territories of Canada, 2001.

Subjects: Households ( $n$ 5643).

Results: Food purchases provided a mean per capita energy availability of 8908 (SE 81$) \mathrm{kJ} / \mathrm{d}(2129$ (SE 19) $\mathrm{kcal} / \mathrm{d}$ ). Over $61 \cdot 7 \%$ of dietary energy came from ultraprocessed products (Group 3), 25.6\% from Group 1 and $12.7 \%$ from Group 2. The overall diet exceeded WHO upper limits for fat, saturated fat, free sugars and $\mathrm{Na}$ density, with less fibre than recommended. It also exceeded the average energy density target of the World Cancer Research Fund/American Institute for Cancer Research. Group 3 products taken together are more fatty, sugary, salty and energydense than a combination of Group 1 and Group 2 items. Only the $20 \%$ lowest consumers of ultra-processed products (who consumed $33.2 \%$ of energy from these products) were anywhere near reaching all nutrient goals for the prevention of obesity and chronic non-communicable diseases.

Conclusions: The 2001 Canadian diet was dominated by ultra-processed products. As a group, these products are unhealthy. The present analysis indicates that any substantial improvement of the diet would involve much lower consumption of ultra-processed products and much higher consumption of meals and dishes prepared from minimally processed foods and processed culinary ingredients.
\end{abstract}

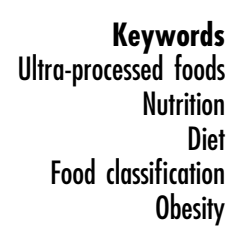

An important cause of the pandemic of overweight and obesity, and of the rapid rise of related chronic diseases especially in lower-income countries, is the corresponding rapid increase in the production and consumption of readily available 'fast' or 'convenience' ready-to-eat or ready-to-heat processed food and drink products. This is now commonly accepted by independent authorities ${ }^{(1-5)}$.

In further support, recent evidence from three cohorts in the USA shows that consumption of various products such as cookies (biscuits), white bread, sweets and desserts, sugar-sweetened drinks, processed meats, and French fries and chips (chips and crisps) is associated with weight gain in adults ${ }^{(6)}$.

Curiously though, the fact that the products in question are processed is almost always either elided or understated, or even overlooked or ignored. Furthermore, food processing as such is not identified in food classifications, such as Canada's Food Guide ${ }^{(7)}$. These still rely on groupings of foods and nutrients developed from systems first devised early last century, when obesity was uncommon and when only a relatively small amount of food was purchased in mass-manufactured form, often for use as ingredients in home cooking. Additionally, food processing is rarely addressed in dietary assessments: methods including the $24 \mathrm{~h}$ recall and FFQ are usually not designed to collect sufficient details that would allow the distinction of foods based on processing.

A new classification has been proposed by a research group at the Faculty of Public Health at the University of São Paulo ${ }^{(8)}$ based on the nature, extent and purpose of 
food processing. Food processing is defined as 'all methods and techniques used by industry to turn whole fresh foods into food products ${ }^{(8)}$. This classification divides all foodstuffs into three groups: unprocessed or minimally processed foods (Group 1); processed culinary ingredients (Group 2); and ultra-processed products (Group 3). These distinctions address social, economic, cultural and other aspects of public health nutrition, as well as biological issues $^{(8,9)}$. Other recent classifications that pay attention to processing in general, in Europe ${ }^{(10)}$ and in Guatemala ${ }^{(11)}$ are based only on the degree of processing, and are therefore of less value.

Using the new classification, researchers at the University of São Paulo have discerned the steady displacement of minimally processed foods and processed culinary ingredients for use at home, by ultra-processed products, over the last three decades in Brazil ${ }^{(12)}$. Such a study has important implications. These products are often or even typically energy-dense, are high in refined starches, sugars, fats or salt, and have a heavy glycaemic load, as well as being often sold in large portion sizes, typically formulated to be extremely palatable and habit-forming, and aggressively advertised and marketed ${ }^{(8,12-15)}$. High consumption of ultra-processed products has also been found to be associated in adolescents with the prevalence of the metabolic syndrome in a cross-sectional study ${ }^{(13)}$.

Consumption of ultra-processed products outside Brazil is at present unknown. The objective of the current paper is to investigate consumption of ultra-processed products in Canada and to assess their association with dietary quality.

\section{Methods}

\section{Data source}

The data analysed in the present study come from the most recent Food Expenditure Survey (FOODEX) conducted in Canada by the Income Statistics Division of Statistics Canada throughout 2001. This survey provides national estimates of expenditures and quantities of food and non-alcoholic drinks bought from stores by households, as well as sociodemographic characteristics of each household.

The FOODEX was conducted throughout the year, covers $98 \%$ of the Canadian population and was carried out in all provinces and territories. A stratified sample was obtained by selecting small geographic areas, followed by the selection of dwellings of similar sociodemographic indicators within these clusters. All estimates presented herein take into account sampling weights provided by FOODEX. A detailed description of the FOODEX sampling strategies is available elsewhere ${ }^{(16)}$.

\section{Data collection}

Data on income and other socio-economic variables were obtained using standardized questionnaires. Data on food and drink purchases were reported by one member of each household using a diary for fourteen consecutive days. The recording included detailed information for each store-bought item in quantities (kilograms or litres) and expenses (\$CAN). Meals and snacks bought in restaurants (including food consumed at home as take-away dishes and deliveries) only had information on expenditure and were not included in our analysis.

Interviewers visited households at the end of the recording phase to make sure all diaries were complete. Quantities of specific food items acquired by the households were taken directly from the expense notebook and missing information on quantities was, as a standard practice, estimated from households of similar geographic and socio-economic characteristics. All food purchase entries were recoded using a list of 194 food items. More detailed information about the data collection and treatment methods is available elsewhere ${ }^{(16)}$.

\section{Data analysis}

For the purposes of the current paper, the FOODEX public-use microdata file was systematically reanalysed using the classification system developed at the University of São Paulo ${ }^{(8,9)}$. The characteristics and examples of foods contained in each of these three groups are summarized in Box 1. Further details on the classification are available elsewhere ${ }^{(8,9)}$.

Individual households were used as the units of analysis ( $n$ 5643). In a first step, purchased food quantities were converted into energy $(\mathrm{kcal} ; 1 \mathrm{kcal}=4 \cdot 184 \mathrm{~kJ})$ using the Canadian Nutrient File (CNF, Version 2010) ${ }^{(17)}$. To do so, each of the 194 codes provided in FOODEX was matched with an appropriate food item in the CNF. The household average daily per capita energy availability and standard error in 2001 were estimated based on all purchased food items ${ }^{(12)}$.

The second step involved assigning food purchases to the three food groups specified above ${ }^{(8,9)}$. Some compromises had to be made: for example, all fruit juices were classified as ultra-processed products because the FOODEX data do not distinguish between unsweetened and sweetened juices, or indeed between fruit juices and 'fruit' drinks containing only some real fruit juice. Mean estimates and standard errors for the relative contribution of each food group and food item to the total household energy availability were then calculated (as a percentage of total energy) for the whole population. Similar calculations were made for population strata corresponding to quintiles of the distribution of the relative contribution of Group 3 products to total energy availability.

In order to assess the likely impact of the consumption of ultra-processed products on human health, we calculated conventional nutritional indicators for the average Canadian household food basket in 2001, and also for two simulated food baskets: one solely containing ultra-processed Group 3 products and the other combining only unprocessed and 


\section{Box 1. Classification of foods based on the nature, extent and purpose of their processing}

Group 1 is made of unprocessed and minimally processed foods. Unprocessed foods are parts of animals immediately after they have been slaughtered and parts of plants after harvesting or collection. Minimally processed foods are unprocessed foods subjected to processes, mostly physical, that do not substantially change the nutritional properties and uses of the original foods. These processes are used to extend the duration and storage of unprocessed foods, and often to reduce the time and effort involved in their preparation. Such processes include cleaning and removal of inedible fractions, portioning, grating, flaking, drying, chilling, freezing, pasteurization, fermentation, fat reduction, vacuum and gas packing, squeezing, and simple wrapping. Group 1 includes fresh or frozen meat, fresh or pasteurized milk and plain yoghurt, whole or polished grains, fresh, frozen or dried fruits and unsweetened fruit juices, fresh and frozen vegetables, whole or peeled roots and tubers, unsalted nuts and seeds, tea and coffee.

Group 2 is made of processed culinary ingredients. These are inexpensive substances extracted from Group 1 foods through physical and chemical transformations, such as refining, milling and hydrolysis. They have nutritional properties and uses entirely different from the original whole foods. Group 2 ingredients include vegetable oils, animal fats, sucrose, and flours and pastas (when made of flour and water). Most are depleted of nutrients and essentially provide energy. However, they are typically inedible in themselves and are rather used in households and also in restaurants to cook and enhance the flavour of meals and dishes prepared with unprocessed or minimally processed foods.

Group 3 is made of ultra-processed food and drink products. These are ready-to-consume/heat industry formulations manufactured from cheap ingredients directly extracted from whole foods, such as oils, fats, sucrose and flours, or processed from components extracted from whole foods such as high-fructose corn syrup, hydrogenated oils, a variety of starches, and the cheap parts or remnants of meat. These products are typically added of several preservatives and cosmetic additives, with little or no content of whole foods. Some ultra-processed products, such as breads and sausages, have been part of dietary patterns in many countries since before industrialization. Others, such as burgers, chips, cookies, cakes, sweets, pizzas, chicken nuggets, energy bars, soft drinks and other sugared drinks, are more recent, at least in the quantity now manufactured. Because of the nature of their formulation (including packaging), these products have a long shelf-life, dispense with culinary preparation and the need for dishes and cutlery, and are intensely palatable and appealing to the senses ${ }^{(21)}$. They are typically energy-dense, with a high content in total, saturated and trans-fats, free sugars and $\mathrm{Na}$, and little or no water, fibre, micronutrients and other protective bioactive compounds existing in whole foods. Marketing campaigns often overtly promote the compulsive consumption of these products including the use of 'discounts' for supersize servings.

minimally processed foods (Group 1) together with processed ingredients (Group 2). In all cases, the energy contribution of each individual food item in the food basket was kept proportional to its energy contribution in the average national household food basket. For instance, if bread and confectionery made up respectively $10 \%$ and $5 \%$ of the total energy in the average national basket, in the simulated basket the same 2:1 proportion was kept.

We then compared dietary indicators in both the average Canadian household food basket and the two simulated food baskets with the recommended ranges for the prevention of chronic diseases specified by the $\mathrm{WHO}^{(1)}$. Dietary indicators (with their recommended ranges) included in the present study were the contribution (\%) to total energy availability from protein (10-15\%), fat (15-30\%), of which saturated fat $(<10 \%)$, carbohydrate $(55-75 \%)$, of which free sugars $(<10 \%)$, and fibre density $(>11 \cdot 1 \mathrm{~g} / 4184 \mathrm{~kJ}(1000 \mathrm{kcal}))$ and $\mathrm{Na}$ density $(<0.90 \mathrm{~g} / 4184 \mathrm{~kJ}(1000 \mathrm{kcal}))$. The recommended limits for these densities were calculated using the total daily recommendation for fibre $(>25 \mathrm{~g} / \mathrm{d})$ and $\mathrm{Na}(<2 \mathrm{~g} / \mathrm{d})$ and the estimated averaged-out energy requirement for men and women with low levels of activity in Canada $(9414 \mathrm{~kJ} / \mathrm{d}(2250 \mathrm{kcal} / \mathrm{d}))^{(18)}$. We also compared the energy density of the overall diet, excluding drinks, with the $<5 \cdot 23 \mathrm{~kJ} / \mathrm{g}(1 \cdot 25 \mathrm{kcal} / \mathrm{g})$ recommended as a goal by the World Cancer Research Fund/American Institute for Cancer Research (WCRF/AICR) ${ }^{(3)}$. For the calculation of energy density, we considered the weight of each food item as usually consumed. To do this, we used the CNF yield correction factor to account for cooking and/or preparation losses $^{(17)}$.

In a second step, we calculated the same nutritional indicators according to quintiles of the distribution of the relative contribution of Group 3 products to total energy availability. Linear regression was also used to test if these indicators varied according to quintile of the relative contribution of Group 3 foods to total energy availability. Adjustment was also made for household income.

All estimates calculated in the study used sampling weights assigned by FOODEX to each household to allow national estimates. Analysis was performed using the statistical software package SPSS version 19 and also accounted for sampling design and weighting effects. 


\section{Results}

All food purchases made by Canadian households for home consumption in 2001 added up to a mean per capita energy availability of 8908 (SE 81) kJ/d (2129 (SE 19) kcal/d).

Table 1 shows the energy share of foodstuffs classified according to the nature, extent and purpose of their processing. In 2001, 25.6\% of all energy purchased by Canadian households was from unprocessed or minimally processed foods (Group 1); $12.7 \%$ was from processed culinary ingredients (Group 2); and a total of $61.7 \%$ was from ultra-processed products (Group 3). In terms of energy, the main items in Group 1 were meat and poultry $(6 \cdot 6 \%)$, milk and plain yoghurt $(6.3 \%)$ and fruits $(3.6 \%)$. Grains including rice and corn contributed very little $(1 \cdot 7 \%)$. The main energy shares for Group 2 were from animal fats $(2 \cdot 8 \%)$, vegetable oils $(2 \cdot 3 \%)$ and table sugar $(2 \cdot 3 \%)$. For Group 3, the main energy shares were from breads $(11.9 \%)$, candies (confectionery), chocolate, ice cream and other sweets $(7 \cdot 1 \%)$, soft drinks and sweetened juices $(6 \cdot 3 \%)$, sugary baked goods $(5 \cdot 8 \%)$, ready-to-eat/heat meals and dishes $(4 \cdot 6 \%)$ and processed meats $(4 \cdot 6 \%)$.
For Table 2, we divided the entire population of households into equal quintiles, according to the amount of ultra-processed products in their diets. These worked out as a range from $33.2 \%$ of total energy in the $20 \%$ of households that purchased least Group 3 items to $84.5 \%$ in the $20 \%$ of households that purchased most Group 3 items.

Table 3 presents conventional nutrient indicators for the average national household food basket in 2001. The overall diet of Canadians in 2001 exceeded the upper limits the WHO has recommended for fat $(37 \cdot 2 v .30 \%)$, saturated fat $(11.6 v .10 \%)$, free sugars $(12 \cdot 3 v .10 \%)$, Na density $(1.6 \quad v \cdot 0 \cdot 9 \mathrm{~g} / 4184 \mathrm{~kJ}(1000 \mathrm{kcal}))$ and energy density (a very substantial difference: $8 \cdot 79 \mathrm{~kJ} / \mathrm{g}(2 \cdot 10 \mathrm{kcal} / \mathrm{g})$ compared with WCRF/AICR's recommended goal of $5 \cdot 23 \mathrm{~kJ} / \mathrm{g}(1 \cdot 25 \mathrm{kcal} / \mathrm{g}))$. It also provided less fibre than the WHO minimum recommendation $(9 \cdot 6 v \cdot 11 \cdot 1 \mathrm{~g} / 4184 \mathrm{~kJ}$ $(1000 \mathrm{kcal}))$. Its protein content was within the recommended range $(13 \cdot 2 v \cdot 10-15 \%)$.

Table 3 shows the same indicators for two simulated food baskets, one made up exclusively of ultra-processed products and the other made up only from unprocessed or minimally processed whole foods together with

Table 1 Contribution of the three food groups to total daily household energy availability in Canada (2001)

\begin{tabular}{lrc}
\hline & & \% of total energy \\
\cline { 2 - 3 } Food group/main items within each group & Mean & SE \\
\hline Group 1: Unprocessed or minimally processed foods & $25 \cdot 6$ & $0 \cdot 2$ \\
Meat and poultry & $6 \cdot 6$ & $0 \cdot 1$ \\
Milk and plain yoghurt & $6 \cdot 3$ & $0 \cdot 1$ \\
Fruits & $3 \cdot 6$ & $0 \cdot 1$ \\
Vegetables & $2 \cdot 4$ & $0 \cdot 1$ \\
Eggs & $1 \cdot 8$ & $0 \cdot 0$ \\
Roots and tubers & $1 \cdot 7$ & $0 \cdot 0$ \\
Grains & $1 \cdot 7$ & $0 \cdot 1$ \\
Fish & $0 \cdot 2$ & $0 \cdot 0$ \\
Other unprocessed or minimally processed foods & $1 \cdot 3$ & $0 \cdot 0$ \\
Group 2: Processed culinary ingredients & $12 \cdot 7$ & $0 \cdot 2$ \\
Fats (butter, lard, cream) & $2 \cdot 8$ & $0 \cdot 1$ \\
Oils (all types) & $2 \cdot 3$ & $0 \cdot 1$ \\
Table sugar & $2 \cdot 3$ & $0 \cdot 1$ \\
Pasta & $1 \cdot 9$ & $0 \cdot 1$ \\
Wheat flour & $1 \cdot 5$ & $0 \cdot 1$ \\
Other processed culinary ingredientst & $1 \cdot 9$ & $0 \cdot 1$ \\
Group 1+Group 2 & $38 \cdot 3$ & $0 \cdot 2$ \\
Group 3: Ultra-processed products & $61 \cdot 7$ & $0 \cdot 2$ \\
Breads & $11 \cdot 9$ & $0 \cdot 1$ \\
Candies, chocolate and ice cream & $7 \cdot 1$ & $0 \cdot 1$ \\
Soft drinks and sweetened fruit juices & $6 \cdot 3$ & $0 \cdot 1$ \\
Sugary baked goods & $5 \cdot 8$ & $0 \cdot 1$ \\
Processed meats & $4 \cdot 6$ & $0 \cdot 1$ \\
Ready-to-eat/heat meals and dishes & $4 \cdot 6$ & $0 \cdot 1$ \\
Cheeses & $3 \cdot 9$ & $0 \cdot 1$ \\
Margarine & $3 \cdot 3$ & $0 \cdot 1$ \\
Sauces & $3 \cdot 2$ & $0 \cdot 1$ \\
Crisps (potato- or grain-based) & $2 \cdot 9$ & $0 \cdot 1$ \\
Breakfast cereals & $2 \cdot 6$ & $0 \cdot 1$ \\
Crackers & $1 \cdot 9$ & $0 \cdot 1$ \\
Other ultra-processed foodsł & $3 \cdot 6$ & $0 \cdot 1$ \\
\hline
\end{tabular}

*Nuts and seeds (unsalted), shellfish, dried herbs, coffee, tea.

tCorn flour, starches, honey, other sugars and sweeteners.

¥Salted and dried or oil-preserved canned fish, canned vegetables, instant noodles, sugared milk drinks. 
Table 2 Contribution (\%) of the three food groups to total daily household energy availability by quintile of the contribution of ultraprocessed products in Canada (2001)

\begin{tabular}{|c|c|c|c|c|c|c|c|c|c|c|}
\hline \multirow[b]{3}{*}{ Food group/main items } & \multicolumn{10}{|c|}{ Quintile of the contribution of Group 3 products to total energy } \\
\hline & \multicolumn{2}{|c|}{1} & \multicolumn{2}{|c|}{2} & \multicolumn{2}{|c|}{3} & \multicolumn{2}{|c|}{4} & \multicolumn{2}{|c|}{5} \\
\hline & Mean & SE & Mean & SE & Mean & SE & Mean & SE & Mean & SE \\
\hline Group 1 & $38 \cdot 8$ & $0 \cdot 7$ & $29 \cdot 6$ & $0 \cdot 3$ & $25 \cdot 2$ & 0.2 & $21 \cdot 7$ & 0.2 & $13 \cdot 0$ & 0.2 \\
\hline Meat and poultry & $10 \cdot 2$ & 0.4 & 8.0 & 0.2 & $6 \cdot 6$ & 0.2 & $5 \cdot 6$ & $0 \cdot 1$ & $2 \cdot 8$ & $0 \cdot 1$ \\
\hline Milk and plain yoghurt & 8.8 & 0.5 & $6 \cdot 6$ & 0.2 & $6 \cdot 2$ & 0.2 & $5 \cdot 6$ & $0 \cdot 1$ & $3 \cdot 8$ & $0 \cdot 1$ \\
\hline Fruits & $5 \cdot 0$ & 0.5 & $4 \cdot 2$ & $0 \cdot 1$ & $3 \cdot 4$ & $0 \cdot 1$ & $3 \cdot 2$ & $0 \cdot 1$ & $2 \cdot 2$ & $0 \cdot 1$ \\
\hline Vegetables & $4 \cdot 0$ & $0 \cdot 2$ & $2 \cdot 8$ & $0 \cdot 1$ & $2 \cdot 2$ & $0 \cdot 1$ & $1 \cdot \overline{8}$ & $0 \cdot 1$ & $1 \cdot 2$ & 0.0 \\
\hline Eggs & $2 \cdot 3$ & $0 \cdot 1$ & $2 \cdot 1$ & $0 \cdot 1$ & 1.9 & 0.1 & 1.5 & $0 \cdot 1$ & $1 \cdot 0$ & $0 \cdot 1$ \\
\hline Roots and tubers & $2 \cdot 2$ & $0 \cdot 1$ & $2 \cdot 2$ & $0 \cdot 1$ & $1 \cdot 8$ & $0 \cdot 1$ & 1.5 & $0 \cdot 1$ & 0.8 & $0 \cdot 1$ \\
\hline Grains & $3 . \overline{9}$ & 0.3 & $1 \cdot \overline{8}$ & $0 \cdot 1$ & 1.6 & 0.1 & $1 \cdot 2$ & $0 \cdot 1$ & 0.6 & $0 \cdot 1$ \\
\hline Fish & $0 \cdot 4$ & 0.0 & 0.3 & 0.0 & 0.2 & $0 \cdot 0$ & 0.2 & $0 \cdot 0$ & $0 \cdot 1$ & 0.0 \\
\hline Other Group $1^{*}$ & $2 \cdot 0$ & 0.2 & $1 \cdot 6$ & $0 \cdot 1$ & $1 \cdot 3$ & 0.1 & $1 \cdot 1$ & $0 \cdot 1$ & 0.5 & 0.0 \\
\hline Group 2 & $28 \cdot 0$ & 0.6 & $16 \cdot 2$ & $0 \cdot 2$ & $10 \cdot 7$ & 0.3 & $5 \cdot 8$ & 0.2 & $2 \cdot 5$ & $0 \cdot 1$ \\
\hline Fats (butter, lard, cream) & 4.5 & 0.3 & $4 \cdot 3$ & 0.2 & $2 \cdot 7$ & $0 \cdot 1$ & $1 \cdot 8$ & $0 \cdot 1$ & 0.6 & $0 \cdot 1$ \\
\hline Oils (all types) & $6 \cdot 9$ & 0.4 & $2 \cdot 5$ & 0.2 & 1.5 & $0 \cdot 1$ & 0.5 & $0 \cdot 1$ & $0 \cdot 1$ & 0.0 \\
\hline Table sugar & $4 \cdot 9$ & 0.2 & $3 \cdot 2$ & $0 \cdot 2$ & $2 \cdot 0$ & $0 \cdot 1$ & $0 \cdot 8$ & $0 \cdot 1$ & 0.4 & $0 \cdot 1$ \\
\hline Pasta & $3 \cdot 0$ & 0.2 & $2 \cdot 4$ & 0.2 & $2 \cdot 2$ & 0.1 & $1 \cdot 4$ & $0 \cdot 1$ & $0 \cdot 7$ & $0 \cdot 1$ \\
\hline Wheat flour & $5 \cdot 1$ & $0 \cdot 3$ & $1 \cdot 5$ & $0 \cdot 1$ & 0.5 & $0 \cdot 1$ & $0 \cdot 2$ & 0.0 & $0 \cdot 1$ & 0.0 \\
\hline Other Group 2† & 3.6 & 0.3 & $2 \cdot 3$ & 0.2 & $1 \cdot 8$ & 0.1 & $1 \cdot 1$ & $0 \cdot 1$ & 0.6 & $0 \cdot 1$ \\
\hline Group 1+Group 2 & $66 \cdot 8$ & 0.5 & $45 \cdot 8$ & 0.4 & $35 \cdot 9$ & 0.2 & $27 \cdot 5$ & 0.2 & $15 \cdot 5$ & $0 \cdot 1$ \\
\hline Group 3 & $33 \cdot 2$ & $0 \cdot 3$ & $54 \cdot 2$ & $0 \cdot 1$ & $64 \cdot 1$ & $0 \cdot 1$ & $72 \cdot 5$ & $0 \cdot 1$ & $84 \cdot 5$ & 0.2 \\
\hline Breads & $7 \cdot \overline{1}$ & 0.2 & $11 \cdot 2$ & 0.2 & $12 \cdot 1$ & 0.3 & $14 \cdot 1$ & 0.3 & $15 \cdot 1$ & $0 . \overline{4}$ \\
\hline Candies, chocolate and ice cream & $3 \cdot 4$ & $0 \cdot 1$ & $5 \cdot 7$ & $0 \cdot 2$ & $7 \cdot 1$ & 0.2 & $8 \cdot 4$ & 0.2 & $10 \cdot 8$ & 0.3 \\
\hline Soft drinks and sweetened fruits juices & $3 \cdot 8$ & $0 \cdot 1$ & $5 \cdot 5$ & 0.2 & $6 \cdot 2$ & 0.2 & $7 \cdot 1$ & 0.2 & $9 \cdot 0$ & 0.3 \\
\hline Sugary baked goods & $2 \cdot 8$ & $0 \cdot 1$ & $4 \cdot 8$ & 0.2 & $5 \cdot 6$ & 0.2 & $7 \cdot 1$ & 0.2 & 8.5 & 0.3 \\
\hline Processed meats & $2 \cdot 4$ & $0 \cdot 1$ & $4 \cdot 6$ & $0 \cdot 1$ & $5 \cdot 2$ & 0.2 & $5 \cdot 1$ & 0.2 & $5 \cdot 9$ & 0.2 \\
\hline Ready-to-eat/heat meals and dishes & $2 \cdot 2$ & $0 \cdot 1$ & $3 \cdot 6$ & $0 \cdot 1$ & $4 \cdot \overline{6}$ & 0.1 & $5 \cdot 6$ & $0 \cdot 1$ & $6 \cdot 9$ & $0 . \overline{3}$ \\
\hline Cheeses & $2 \cdot 5$ & $0 \cdot 1$ & $3 \cdot 8$ & $0 \cdot 1$ & $4 \cdot 4$ & $0 \cdot 1$ & $4 \cdot 4$ & 0.2 & $4 \cdot 3$ & 0.2 \\
\hline Margarine & $1 \cdot 4$ & $0 \cdot 1$ & $2 \cdot 3$ & $0 \cdot 1$ & 3.5 & 0.2 & 3.9 & 0.2 & $5 \cdot 1$ & 0.3 \\
\hline Sauces & $1 \cdot 7$ & $0 \cdot 1$ & $2 \cdot 8$ & $0 \cdot 1$ & 3.5 & $0 \cdot 1$ & $4 \cdot 0$ & 0.2 & $4 \cdot 2$ & $0 \cdot 2$ \\
\hline Crisps (potato- and grain-based) & $1 \cdot 3$ & $0 \cdot 1$ & $2 \cdot 4$ & $0 \cdot 1$ & $3 \cdot 2$ & 0.2 & 3.5 & 0.2 & 4.5 & 0.3 \\
\hline Breakfast cereals & $1 \cdot 4$ & $0 \cdot 1$ & $2 \cdot 7$ & $0 \cdot 1$ & $2 \cdot \overline{8}$ & 0.1 & $3 \cdot 1$ & $0 \cdot 1$ & $2 \cdot 8$ & 0.2 \\
\hline Crackers & 0.9 & 0.1 & 1.5 & 0.1 & $2 \cdot 0$ & 0.1 & $2 \cdot 4$ & 0.1 & 2.9 & 0.1 \\
\hline Other Group 3‡ & $2 \cdot 3$ & $0 \cdot 1$ & $3 \cdot 3$ & $0 \cdot 1$ & 3.9 & 0.1 & $3 \cdot 8$ & 0.2 & 4.5 & $0 \cdot 1$ \\
\hline
\end{tabular}

Group 1: unprocessed /minimally processed foods; Group 2: processed culinary ingredients; Group 3: ultra-processed products.

${ }^{*}$ Nuts and seeds (unsalted), shellfish, dried herbs, coffee, tea.

tCorn flour, starches, honey, other sugars and sweeteners.

$\ddagger$ Salted and dried or oil-preserved canned fish, canned vegetables, instant noodles, sugared milk drinks.

Table 3 Nutrient profile indicators of the average food basket and of two simulated food baskets in Canada (2001)

\begin{tabular}{|c|c|c|c|c|c|c|}
\hline \multirow[b]{2}{*}{ Indicator } & \multicolumn{2}{|c|}{ Average food basket } & \multicolumn{2}{|c|}{$\begin{array}{l}\text { Food basket restricted } \\
\text { to Group } 1 \text { and Group } 2\end{array}$} & \multicolumn{2}{|c|}{$\begin{array}{l}\text { Food basket restricted } \\
\text { to Group } 3 \text { products }\end{array}$} \\
\hline & Mean & $\mathrm{SE}$ & Mean & SE & Mean & $\mathrm{SE}$ \\
\hline \multicolumn{7}{|l|}{$\%$ of energy from: } \\
\hline Proteins $(\%)$ & $13 \cdot 6$ & $0 \cdot 1$ & $19 \cdot 2$ & $0 \cdot 1$ & $10 \cdot 1$ & $0 \cdot 1$ \\
\hline Total carbohydrates (\%) & $49 \cdot 2$ & $0 \cdot 2$ & $47 \cdot 0$ & $0 \cdot 2$ & $50 \cdot 6$ & $0 \cdot 2$ \\
\hline Free sugars (\%) & $12 \cdot 3$ & $0 \cdot 1$ & $3 \cdot 8$ & 0.0 & $18 \cdot 6$ & $0 \cdot 1$ \\
\hline Total fats $(\%)$ & $37 \cdot 2$ & $0 \cdot 1$ & $33 \cdot 8$ & $0 \cdot 3$ & $39 \cdot 3$ & 0.2 \\
\hline Saturated fats (\%) & $11 \cdot 6$ & $0 \cdot 1$ & $11 \cdot 3$ & $0 \cdot 1$ & $11 \cdot 7$ & $0 \cdot 1$ \\
\hline Na density (g/4184 kJ (1000 kcal)) & $1 \cdot 6$ & $0 \cdot 3$ & $1 \cdot 4$ & $0 \cdot 0$ & $1 \cdot 7$ & $0 \cdot 0$ \\
\hline Fibre density (g/4184 kJ (1000 kcal)) & $9 \cdot 6$ & $0 \cdot 1$ & $14 \cdot 8$ & $0 \cdot 0$ & $6 \cdot 8$ & $0 \cdot 0$ \\
\hline Energy density* $(\mathrm{kJ} / \mathrm{q})$ & $8 \cdot 8$ & 0.0 & $5 \cdot 4$ & 0.0 & $11 \cdot 7$ & 0.0 \\
\hline Energy density* $(\mathrm{kcal} / \mathrm{g})$ & $2 \cdot 1$ & 0.0 & $1 \cdot 3$ & 0.0 & $2 \cdot 8$ & 0.0 \\
\hline
\end{tabular}

Group 1, unprocessed/minimally processed foods; Group 2, processed culinary ingredients; Group 3, ultra-processed products.

*Drinks excluded.

processed culinary ingredients. The food basket containing no ultra-processed products is much higher in protein $(19 \cdot 2 v \cdot 10 \cdot 1 \%)$ and fibre $(14 \cdot 8 v \cdot 6 \cdot 8 \mathrm{~g} / 4184 \mathrm{~kJ}$ $(1000 \mathrm{kcal}))$; and is lower in fat $(33 \cdot 8 v \cdot 39 \cdot 3 \%)$, slightly lower in saturated fat $(11 \cdot 3 v \cdot 11 \cdot 7 \%)$, very much lower in free sugars $(3.8 v .18 \cdot 6 \%)$ and lower in $\mathrm{Na}(1.4 v .1 .7$ $\mathrm{g} / 4184 \mathrm{~kJ}(1000 \mathrm{kcal})$ or $3 \cdot 1 \mathrm{v} \cdot 3 \cdot 8 \mathrm{~g} / \mathrm{d})$. The diet made up only from Group 1 foods and Group 2 ingredients is also 
Table 4 Nutrient profile indicators of the overall diet by quintile of the contribution of ultra-processed products to total energy in food purchases in Canada (2001)

\begin{tabular}{|c|c|c|c|c|c|c|c|c|c|c|}
\hline \multirow[b]{3}{*}{ Indicator } & \multicolumn{10}{|c|}{ Quintile of the contribution of Group 3 products to total energy } \\
\hline & \multicolumn{2}{|c|}{1} & \multicolumn{2}{|c|}{2} & \multicolumn{2}{|c|}{3} & \multicolumn{2}{|c|}{4} & \multicolumn{2}{|c|}{5} \\
\hline & Mean & SE & Mean & SE & Mean & SE & Mean & SE & Mean & SE \\
\hline \multicolumn{11}{|l|}{$\%$ of energy from: } \\
\hline Proteins (\%) & $14 \cdot 9$ & $0 \cdot 1$ & $14 \cdot 1$ & $0 \cdot 1$ & $13 \cdot 8$ & $0 \cdot 1$ & $13 \cdot 4$ & $0 \cdot 1$ & $11 \cdot 6$ & $0 \cdot 1 \ddagger$ \\
\hline Total carbohydrates (\%) & $50 \cdot 0$ & $0 \cdot 4$ & $49 \cdot 5$ & $0 \cdot 3$ & $49 \cdot 6$ & $0 \cdot 3$ & $49 \cdot 6$ & $0 \cdot 2$ & $50 \cdot 2$ & $0 \cdot 3$ \\
\hline Free sugars (\%) & $9 \cdot 2$ & $0 \cdot 0$ & $11 \cdot 6$ & $0 \cdot 0$ & $12 \cdot 0$ & $0 \cdot 0$ & $13 \cdot 5$ & $0 \cdot 1$ & $15 \cdot 1$ & $0 \cdot 1 \ddagger$ \\
\hline Total fats $(\%)$ & $35 \cdot 1$ & $0 \cdot 4$ & $36 \cdot 4$ & $0 \cdot 3$ & $36 \cdot 6$ & $0 \cdot 3$ & $37 \cdot 0$ & $0 \cdot 3$ & $38 \cdot 2$ & $0.3 \ddagger$ \\
\hline Saturated fats (\%) & $11 \cdot 4$ & $0 \cdot 2$ & $12 \cdot 0$ & $0 \cdot 1$ & $11 \cdot 8$ & $0 \cdot 1$ & $11 \cdot 4$ & $0 \cdot 1$ & $11 \cdot 4$ & $0 \cdot 1$ \\
\hline Na density (g/4184 kJ (1000 kcal)) & $1 \cdot 1$ & $0 \cdot 4$ & $1 \cdot 4$ & 0.3 & 1.5 & $0 \cdot 3$ & $1 \cdot 6$ & $0 \cdot 3$ & $1 \cdot 6$ & $0 \cdot 3 \ddagger$ \\
\hline Fibre density (g/4184 kJ (1000 kcal)) & $11 \cdot 2$ & $0 \cdot 0$ & $10 \cdot 1$ & $0 \cdot 0$ & $9 \cdot 7$ & $0 \cdot 0$ & $9 \cdot 1$ & $0 \cdot 0$ & $8 \cdot 0$ & $0 \cdot 1 \ddagger$ \\
\hline Energy density* $(\mathrm{kJ} / \mathrm{g})$ & $7 \cdot 5$ & $0 \cdot 4$ & $8 \cdot 4$ & 0.4 & $8 \cdot 8$ & $0 \cdot 4$ & $8 \cdot 8$ & 0.4 & $9 \cdot 6$ & $0.4 \ddagger$ \\
\hline Energy density* (kcal/g) & $1 \cdot 8$ & $0 \cdot 1$ & $2 \cdot 0$ & $0 \cdot 1$ & $2 \cdot 1$ & $0 \cdot 1$ & $2 \cdot 1$ & $0 \cdot 1$ & $2 \cdot 3$ & $0 \cdot 1 \ddagger$ \\
\hline Total energy $(\mathrm{kJ} / \mathrm{d}) \dagger$ & 10008 & 254 & 9548 & 180 & 9665 & 164 & 9247 & 153 & 8134 & 147 \\
\hline Total energy $(\mathrm{kcal} / \mathrm{d}) \dagger$ & 2392 & $60 \cdot 6$ & 2282 & $43 \cdot 1$ & 2310 & $39 \cdot 2$ & 2210 & $36 \cdot 6$ & 1944 & $35 \cdot 1$ \\
\hline
\end{tabular}

${ }^{*}$ Drinks excluded.

tFrom store-bought food which represents $70-72 \%$ of all food expenditures for quintiles $1-4$ and $65 \%$ for quintile 5 .

$\ddagger$ Significant linear trend across all quintiles $(P<0 \cdot 01)$.

very much lower in energy density $(5.4 \mathrm{~kJ}(1.3 \mathrm{kcal}) v$. $11 \cdot 7 \mathrm{~kJ}(2 \cdot 8 \mathrm{kcal}) / \mathrm{g})$.

Table 4 shows nutrient indicators as these vary depending on the amount of ultra-processed products in total purchased energy. The food basket of the lowest quintile compared with the highest quintile is higher in protein $(14.9 v \cdot 11 \cdot 6 \%)$ and fibre $(11.2 v .8 .0 \mathrm{~g} / 4184 \mathrm{~kJ}$ $(1000 \mathrm{kcal}))$; and is lower in fat $(35 \cdot 1 v \cdot 38 \cdot 2 \%)$ and much lower in free sugars $(9 \cdot 2 v \cdot 15 \cdot 1 \%), \mathrm{Na}(1 \cdot 1 v \cdot 1 \cdot 6 \mathrm{~g} / 4184 \mathrm{~kJ}$ $(1000 \mathrm{kcal}))$ and energy density $(7.53 \mathrm{~kJ}(1.80 \mathrm{kcal}) v .9 \cdot 62 \mathrm{~kJ}$ $(2 \cdot 30 \mathrm{kcal}) / \mathrm{g})$. There is a significant linear trend across all quintiles for all these indicators $(P<0 \cdot 01)$ which remains after adjustment for family income.

\section{Discussion}

In the present paper we use a new food classification based on the nature, extent and purpose of food processing and apply it to national data on household food purchases made in Canada in 2001. Our purpose has been to investigate the contribution of ultra-processed products in the Canadian diet and to assess their association with dietary quality.

A previous paper using the same classification and similar methods has reported findings in $\mathrm{Brazil}^{(8)}$. These are very different from Canada. The contribution of Group 3 products in Brazil in 2002-2003, at 20.0\%, was less than a third of the $61.7 \%$ found in Canada in 2001 . The contribution of Group 1 foods and Group 2 ingredients in Brazil, at $42.5 \%$ and $37.5 \%$ for a total of $80 \%$, was correspondingly more than twice the $25.6 \%$ and $12.7 \%$ for the total of $38.3 \%$ found in Canada.

There are other striking differences between Brazilian and Canadian diets as reflected in household expenditure. In Brazil the top three contributors to energy from
Group 1 foods are rice $(16 \cdot 6 \%)$, meat and poultry $(8 \cdot 2 \%)$ and beans (6.3\%). In Canada the top three items are meat and poultry $(6.6 \%)$, milk and plain yoghurt $(6.3 \%)$ and fruits $(3.6 \%)$, and the contribution of grains such as rice and corn is almost negligible (1.7\%). By contrast, the energy share of plant oils (11.3\%) and table sugar $(12.4 \%)$ were both five times higher in Brazil than in Canada $(2.3 \%$ and $2.3 \%$, respectively). What these data show is that food preparation and cooking at the time of the surveys was still normal in Brazil; whereas in Canada only a fraction of the population still regularly prepared and cooked meals at home, and instead consumed readyto-eat or ready-to-heat ultra-processed products. Even excluding food eaten away from home and also takeaway products, the energy share of ready-to-eat/heat dishes and meals in Canada (4.6\%) was nine times that in Brazil $(0 \cdot 6 \%)$.

Approximately $75 \%$ of the free sugars consumed in Canada came from soft drinks, juices, candies (confectionery), chocolates, ice creams, fruit preparations, pastries, cakes and cookies (biscuits). These ready-to-eat or ready-to-drink sweet snacks accounted for $19 \cdot 2 \%$ of all energy bought by Canadian households. In Brazil the same foods accounted for only $6.6 \%$ of total energy. The consumption of soft drinks and sweetened juices was four times higher in Canada (6.3\%) than in Brazil $(1 \cdot 6 \%)^{(8)}$. By their nature, Group 3 products are liable to be consumed in the form of snacks. In Canada in 2004, products specifically identified as snacks accounted for $23 \%$ of energy intake, more than consumed at breakfast ${ }^{(19)}$.

In Brazil, a positive relationship between family income and consumption of ultra-processed products was reported $^{(12)}$. However in Canada, differences in the energy share of ultra-processed products between income groups were very small, ranging from $60.3 \%$ in the lower income group to $62 \cdot 8 \%$ in the upper income 
group (data not shown). The driving force here may be the higher relative cost of ultra-processed products in Brazil compared with Canada. Preliminary analysis of food expenditure surveys conducted in Brazil and the UK shows that the cost of ultra-processed products relative to other foods is much higher in Brazil ${ }^{(20)}$.

\section{Dietary quality of ultra-processed products}

Judged in terms of conventional nutrient indicators, the data presented in the current paper demonstrate that ultraprocessed products, as a whole, are unhealthy. Indeed, when compared with a diet made of Group 1 foods and Group 2 ingredients, a diet containing only Group 3 products contains less than half the dietary fibre, almost six times the free sugars, and significantly more $\mathrm{Na}$ and fat. There is not much difference in saturated fat. Perhaps most significant of all, the diet made up only of ultra-processed products is more than twice as energy-dense as the other one.

These results led to a crucial finding, which has influenced the analysis and conclusions of this and other papers $^{(8,12)}$. Group 2 ingredients are mostly processed fats, oils, sugar and starches. They are by themselves therefore energy-dense and depleted in many nutrients. It seems logical therefore that recommendations designed to improve public health should target them - and of course they can be consumed excessively. However, they are not consumed by themselves. As culinary ingredients they are combined with Group 1 foods. What the present study and the Brazilian one ${ }^{(12)}$ indicate is that actual diets mainly made up from Group 1 foods and Group 2 ingredients are much less energy-dense than diets mainly made up from Group 3 products, and are also higher in dietary fibre and lower in fat, free sugars and $\mathrm{Na}$. We emphasize this finding here, because it is counterintuitive. This conclusion is, we believe, is of great importance in specifying dietary guidelines, in setting public health nutrition policies, and in undertaking interventions and programmes designed to prevent and control disease and to protect and improve general well-being.

\section{Making the Canadian diet bealthy}

Our data show that food supplies and dietary patterns dominated by ultra-processed products, as in Canada, exceed WHO upper limits for fat, free sugars and $\mathrm{Na}$, and fall short of recommended levels of dietary fibre. Perhaps even more important, the more ultra-processed products that are consumed, the higher is the energy density of the diet.

Overall quality of diets decreases as the proportion of ultra-processed products increases. However, examination of the quintile of Canadian households in which consumption of ultra-processed products is lowest, at $33.2 \%$ of total energy, shows that these diets are not far away from WHO recommendations. They are adequate in protein $(14.9 v, 10-15 \%)$ and in dietary fibre $(11 \cdot 2 v$. $11 \cdot 1 \mathrm{~g} / 4184 \mathrm{~kJ}(1000 \mathrm{kcal}))$. They just come within the upper limit recommended for free sugars $(9 \cdot 2 v .10 \%)$ and are not far above the upper limit for $\mathrm{Na}(1 \cdot 1 \mathrm{v} .0 \cdot 9$ $\mathrm{g} / 4184 \mathrm{~kJ}(1000 \mathrm{kcal}))$. Where they do not correspond is in fat $(35 \cdot 1 v$. an upper limit of $30 \%)$. Saturated fat is also somewhat above the upper limit $(11.4 v$. an upper limit of $10 \%)$. However, at $7.53 \mathrm{~kJ}(1.80 \mathrm{kcal}) / \mathrm{g}$, the energy density is still much higher than the WCRF/AICR recommended target of $5 \cdot 23 \mathrm{~kJ}(1 \cdot 25 \mathrm{kcal}) / \mathrm{g}$.

It would be possible to adjust the diets of this fifth of the Canadian population by making changes to the composition of Group 1 foods. For instance, preferring lean cuts of meat, together with preferring $1 \%$ low-fat milk, without making any other changes, would lower saturated fat consumption from 11.4 to $9.9 \%$ of total energy. Changing from red meat to white meat and fish, or substituting legumes for some meat, would reduce saturated fat consumption further.

Further changes to bring nutrient indicators of this fifth of the Canadian population well within WHO recommendations for fat, saturated fat, free sugars and $\mathrm{Na}$, and to come closer to the WCRF/AICR goal for energy density, would be possible only by making changes in the frequency of consumption of some ultra-processed products. For example, if sugared beverages, candies and salty snacks ( $8.5 \%$ of total energy in this group) were consumed only very occasionally if at all, dietary energy from ultraprocessed products would fall under a third of total energy.

A main finding of the study is that $80 \%$ of the Canadian population has diets that include more than $50 \%$ of ultraprocessed products in terms of energy. It is not possible to manipulate these diets to make them to correspond with WHO and other recommendations designed to prevent and control obesity and related chronic diseases without radical reductions in ultra-processed products. This would mean a fundamental change, from a reliance on ready-to-eat or ready-to-heat Group 3 products to preparation and cooking of meals based on Group 1 foods and Group 2 ingredients.

\section{Study limitations}

The present study has three main limitations, all due to the limitations of using household food purchases as a proxy of individual food consumption.

First, not all food purchased is necessarily consumed. Since most wastage is of perishable Group 1 foods, it is likely that the relative proportion of Group 3 products in Canadian diets as actually consumed is somewhat higher than shown here. Second, the data analysed do not include purchases in restaurants or take-away and home deliveries. Since much of these purchases is liable to be of ultra-processed products, if included in the calculations they would have the general effect of increasing the percentage of such products in Canadian diets.

To attenuate the above limitations in regard to the dietary impact of ultra-processed products, we have presented all nutrient indicators in relative and not 
absolute terms. The most important finding from our analyses is the fact that the overall quality of diets decreases as the proportion of ultra-processed products increases. This would be in doubt only if the association between nutrient indicators and the proportion of ultraprocessed products in wasted foods, and also in foods bought from restaurants or fast-food outlets, was very different from and opposite to the association found for foods bought from stores and consumed.

A third limitation is that the unit of analysis of food purchase surveys was households and not individuals. It is not possible to extrapolate our findings to all household members. This limitation applies to the diet share of ultra-processed products as well as to their impact on the quality of the overall diet.

Future studies on the share and impact of ultra-processed products should use revised food frequency and $24 \mathrm{~h}$ recall questionnaires that make clear distinctions between the intakes of Group 1 foods, Group 2 ingredients and Group 3 ultra-processed products and then, with these new instruments, make surveys of complete diets. These surveys will be important to confirm our findings derived from household food purchases. Furthermore, such surveys should also collect data on BMI and disease outcomes to increase the understanding of the impact of the consumption of ultra-processed products.

\section{Conclusions}

The present paper shows that $61.7 \%$ of the dietary energy in Canada, as measured by the 2001 national household food expenditure survey, comes from ultra-processed products. We also demonstrate that, as a whole, ultraprocessed products are unhealthy as compared with the combination of minimally processed foods and processed culinary ingredients. The data presented here support our previous proposal that diets high in or dominated by ultra-processed products cannot meet WHO and other dietary recommendations designed to prevent and control obesity and chronic diseases ${ }^{(1)}$. Only the one-fifth of the Canadian population that consumes $33 \cdot 2 \%$ of energy in the form of ultra-processed products is anywhere near reaching all nutrient goals for the prevention of obesity and chronic non-communicable diseases.

A provisional conclusion, at least for Canada, is that a healthy diet would contain less than one-third of energy in the form of ultra-processed products. This could be achieved only if diets are based primarily on meals and dishes prepared with minimally processed foods and processed culinary ingredients.

\section{Acknowledgements}

Sources of funding: This manuscript was supported by postdoctoral fellowship funds from Fundação de Amparo à Pesquisa do Estado de São Paulo (FAPESP; \#2011/08425-5 and \#2010/08421-7). Conflicts of interest: The authors declare no conflicts of interest. Authors' contributions: The empirical design was planned and supervised by C.A.M. and conducted by J.-C.M. and A.P.B.M. The initial draft was conducted by J.-C.M. following extensive discussions with C.A.M., R.B.L. and R.M.C. Successive drafts were developed by C.A.M. and G.C., with comments by all co-authors. Each author has seen and approved the content of the submitted manuscript.

\section{References}

1. World Health Organization (2003) Diet, Nutrition and the Prevention of Chronic Diseases. Report of the Joint WHO/ FAO Expert Consultation. WHO Technical Report Series no. 916. Geneva: WHO.

2. World Cancer Research Fund/American Institute for Cancer Research (2007) Food, Nutrition, Physical Activity, and the Prevention of Cancer: A Global Perspective. Washington, DC: AICR.

3. World Cancer Research Fund/American Institute for Cancer Research (2009) Policy and Action for Cancer Prevention. Food, Nutrition, and Physical Activity: A Global Perspective. Washington, DC: AICR.

4. United Nations Standing Committee on Nutrition (2010) Progress in Nutrition. Sixth Report on the World Nutrition Situation. Geneva: UNSCN.

5. Institute of Medicine (2006) Food Marketing to Children and Youth: Threat or Opportunity? Washington, DC: IOM.

6. Mozaffarian D, Hao T, Rimm EB et al. (2011) Changes in diet and lifestyle and long term weight gain in women and men. N Engl J Med 364, 2392-2404.

7. Health Canada (2011) Canada's Food Guide. http:// www.hc-sc.gc.ca/fn-an/food-guide-aliment/index-eng.php (accessed March 2012).

8. Monteiro CA, Levy RB, Claro RM et al. (2010) A new classification of foods based on the extent and purpose of their processing. Cad Saude Publica 26, 2039-2049.

9. Monteiro CA (2010) The big issue is ultra-processing. World Nutr 1, 237-269.

10. Slimani N, Deharveng G, Southgate DAT et al. (2009) Contribution of highly industrially processed foods to the nutrient intakes and patterns of middle-aged populations in the European Prospective Investigation into Cancer and Nutrition study. Eur J Clin Nutr 63, Suppl. 4, S206-S225.

11. Asfaw A (2011) Does consumption of processed foods explain disparities in the body weight of individuals? The case of Guatemala. Health Econ 20, 184-195.

12. Monteiro CA, Levy RB, Claro RM et al. (2011) Increasing consumption of ultra-processed foods and likely impact on human health: evidence from Brazil. Public Health Nutr 14, 5-13.

13. Tavares LF, Fonseca SC, Garcia Rosa ML et al. (2011) Relationship between ultra-processed foods and metabolic syndrome in adolescents from a Brazilian Family Doctor Program. Public Health Nutr (Epublication ahead of print version).

14. Ludwig DS (2011) Technology, diet, and the burden of chronic disease. JAMA 305, 1352-1353

15. Monteiro CA, Gomes FS \& Cannon G (2010) The snack attack. Am J Public Health 100, 975-981.

16. Statistics Canada (2003) 2001 Food Expenditure Survey Public-use Microdata Files. Ottawa: Income Statistics Division of Statistics Canada. 
17. Health Canada (2012) Canadian Nutrient File. http:// webprod3.hc-sc.gc.ca/cnf fce/index-eng.jsp (accessed March 2012).

18. Health Canada (2012) Estimated energy requirements. http://www.hc-sc.gc.ca/fn an/food-guide-aliment/basicsbase/1_1_1-eng.php (accessed March 2012).
19. Garriguet D (2007) Canadians' eating habits. Health Rep 18, 17-32.

20. Monteiro CA (2011) The big issue is ultra-processing: the price and value of meals. World Nutr 2, 271-282.

21. Kessler DA (2009) The End of Overeating. Taking Control of the Insatiable American Appetite. New York: Rodale. 